Esta revista forma parte del acervo de la Biblioteca Jurídica Virtual del Instituto de Investigaciones Jurídicas de la UNAM

\title{
La observación, la justicia electoral y el proceso democrático en México. Cumplimiento de la legalidad electoral
}

\section{Juan Carlos Ruiz Espíndola*}

\section{Sumario:}

I. Introducción

II. Fundación Estado y Sociedad, A.C. Informe de observación electoral 2012. Síntesis de los principales temas

III. Comisión Mexicana de Derechos Humanos, A.C. Proyecto justicia electoral 2012. Una observación a la luz de la reforma constitucional de los derechos humanos

IV. Ciudadanos en movimiento para el Desarrollo A.C. (CiudaDes)

V. El Colegio de México

VI. Universidad Autónoma de Chiapas. Diagnóstico de las fortalezas y debilidades de la fiscalización electoral en México

VII. Fuentes consultadas

* Maestro en Derecho por la UNAM, especialista en Justicia Electoral por el Tribunal Electoral del Poder Judicial de la Federación y en Derecho Corporativo por la Universidad Panamericana; imparte las cátedras de Derecho Electoral y Propiedad Intelectual.

D. R. @ 2013. PNUD-UNAM, Instituto de Investigaciones Jurídicas. Revista Mexicana de Derecho Electoral, Especial sobre Observación Electoral 2012, núm. 4, pp. 135-152, México, D. F. 
Esta revista forma parte del acervo de la Biblioteca Jurídica Virtual del Instituto de Investigaciones Jurídicas de la UNAM www.juridicas.unam.mx

\section{Resumen:}

Se expone la participación de organizaciones de la sociedad civil y las instituciones académicas y de investigación apoyadas por el Fondo de Apoyo a la Observación Electoral 2012.

Se enfatizan temas y esquemas que pueden constituir propuestas de reforma al Cofipe. Para ello, se incluyen conclusiones expuestas por: 1) la Fundación Estado y Sociedad, A.C. Destaca que la relación actual del Instituto Federal Electoral (IFE) y el Tribunal Electoral del Poder Judicial de la Federación (TEPJF) es compleja y que para consolidar una cultura democrática en materia de las instituciones significa consolidar el pleno reconocimiento de los actores políticos; 2) la Comisión Mexicana de Derechos Humanos, A.C., refiere la responsabilidad que tienen las autoridades electorales y los partidos políticos como autores principales en el proceso electoral; 3) Ciudadanos en movimiento para el Desarrollo A.C., detectó tres rubros que impactan la legalidad electoral: campañas electorales, redes sociales y jornada electoral; 4) El Colegio de México destaca que las elecciones son cada vez más competidas, plurales y precisas, pero cada vez más sospechosas, rechazadas e impugnadas; 5) la Universidad Autónoma de Chiapas analiza el control de la financiación y el gasto político electoral. ${ }^{1}$

Palabras clave: derechos humanos, fiscalización, compra y coacción del voto, justicia, judicialización electoral, votaciones atípicas, topes de gastos de campaña, monitoreo de medios.

1 Jornada Temática Observación Electoral en México: Lecciones aprendidas y visión a futuro, celebrada el 15 de noviembre de este año, en la Facultad Latinoamericana de Ciencias Sociales, sede México. 


\section{Introducción}

La síntesis que me permito desarrollar, considera entre otros ejes, las conclusiones que estimé de mayor relevancia, vertidas en la Jornada Temática Observación Electoral en México: Lecciones aprendidas y visión a futuro, celebrada el 15 de noviembre de este año, en la Facultad Latinoamericana de Ciencias Sociales, sede México. Al respecto, participaron dos organizaciones de la sociedad civil, cinco instituciones académicas y centros de investigación, y un organismo internacional.

De los informes que me permití analizar, y que corresponden a la Fundación Estado y Sociedad, A.C.; la Comisión Mexicana de Derechos Humanos, A.C.; Ciudadanos en movimiento para el Desarrollo A.C.; El Colegio de México y la Universidad Autónoma de Chiapas, enfatizo algunos temas y esquemas que me parecen extremadamente importantes para su escrutinio público y que constituyen apartados que traen aparejada una serie de propuestas en el ámbito de la legalidad electoral, para una eventual reforma al Código Federal de Instituciones y Procedimientos Electorales (Cofipe).

Los grandes temas son, por un lado, el sentido de las resoluciones del Tribunal Electoral del Poder Judicial de la Federación, aspectos sobre la judicialización de los procesos electorales, los criterios de interpretación contrapuestos, emitidos por el Instituto Federal Electoral y el máximo órgano jurisdiccional en la materia, así como las votaciones atípicas, y por otro lado, el modelo de financiamiento y procedimiento fiscalizador de los recursos de los partidos políticos, en los que se resaltan temas de precampañas y campañas, integración de informes financieros, y lo más interesante, que aún en nuestras normas no está previsto, el hecho de que la fiscalización no tenga incidencia con los resultados electorales, por lo que concluyo, resulta trascendental el que se promueva una iniciativa de ley federal de fiscalización, que sirva de base para una posible declaración de invalidez de la elección, entre otros.

También, saltan a la vista los significativos esquemas y soluciones a "problemáticas" de los procesos electorales, como lo son: hacer responsables a los candidatos por sus gastos de campaña; la impostergable tarea de crear un sistema electrónico de rendición de cuentas, así como uno de verificación contable autoaplicativo, y propiciar la 
Esta revista forma parte del acervo de la Biblioteca Jurídica Virtual del Instituto de Investigaciones Jurídicas de la UNAM

coadyuvancia de diversas autoridades en acciones de fiscalización de los recursos de los partidos políticos.

Otra arista que arrojan los informes tiene que ver con la revisión de los topes de gastos de campaña y su vinculación con las causales de nulidad de la elección, así como en relación con temas tan relevantes como la individualización de las sanciones; derechos humanos, en particular el derecho a la información; encuestas; fiscalización autoaplicativa desde los informes de los partidos políticos y estrategias de fiscalización; financiamiento público; veto popular; autonomía de gestión del IFE; cuotas de género y contraloría ciudadana; en tanto cada tema corresponde a aspectos de legalidad y justicia electoral.

Por razón de método, procedo a exponer mi análisis en los términos siguientes.

\section{Fundación Estado y Sociedad, A. C. Informe de observación electoral 2012. Síntesis de los principales temas}

Aun cuando la relación del IFE y el TEPJF sigue siendo compleja, deben consolidar conjuntamente una cultura democrática con el pleno reconocimiento de los actores políticos en ámbitos como el de limpieza en la elección, credibilidad de los resultados electorales, imparcialidad y fortalecimiento, así como modernización del régimen electoral, que será factible solamente si hay voluntad de las élites gobernantes.

Lo anterior es así, porque aún se percibe que las decisiones de las y los consejeros electorales tienen que ver con su origen de selección y en ese sentido tienden a apoyar diversa estrategia o impulsar determinada reforma, lo mismo ocurre con los magistrados del TEPJF, ya que sus decisiones y desarrollo de sus funciones - también así lo estimo-, están orientadas por sus tendencias y lealtades a las dirigencias partidistas que los pusieron o impulsaron.

Es evidente que las élites de gobernantes que ostentan el poder, optan por mantener su control sobre los presupuestos públicos ampliando la creación de redes y organizaciones que justifiquen su actuar, no obstante que se alejen de políticas incluyentes de carácter político desde la sociedad civil y de transitar a una sociedad más democrática, 
a partir de los principios de respeto y promoción de los derechos humanos, en su modalidad de derechos políticos.

El informe que se analiza, observa un renovado comportamiento de los partidos políticos ante las nuevas disposiciones contenidas en la Ley General del Sistema de Medios de Impugnación en Materia Electoral (LGSMIME) y las reformas al artículo 1o. de la CPEUM.

$\mathrm{Al}$ respecto, vale la pena y es procedente que las normas e instituciones se adecuen al cambio para evitar situaciones de crisis y deterioro institucional cada seis años en elecciones presidenciales, particularmente la creación de un mecanismo de investigación y análisis con la participación de organizaciones de la sociedad civil, con esquemas que incluyan: presupuesto de egresos; estudio de recursos utilizados por los partidos y candidatos, esto con el fin de que se proyecte una nueva ingeniería electoral institucional.

El pronunciamiento que abiertamente abanderó las decisiones del TEPJF consistió en proteger el régimen interno de los partidos políticos, toda vez que así lo dispone la ley vigente en un apartado específico que establece "el sistema de partidos", por lo que debe garantizarse su integridad, por ello, su intervención y forma de resolver estuvo acotada "en aquellos casos que señale estrictamente la norma o a ley".

Lo anterior, se reflejó contundentemente en algunos datos contenidos en estadísticas que contemplaron el total de las sentencias emitidas por el TEPJF, y que de ese total, en aproximadamente el 85\%, no se concedieron en favor del ciudadano, lo que se traduce en un franco fortalecimiento de las cúpulas partidistas y sus prácticas tradicionales del sistema de hegemonías.

A partir del análisis de algunos juicios de protección de derechos ciudadanos, a la luz de un estudio deontológico, jurisprudencial y procesal electoral, se concluye en la imperiosa necesidad de crear una visitaduría para la defensa de derechos políticos electorales, misma que por su naturaleza, debe ser adscrita a la Comisión Nacional de Derechos Humanos y, por supuesto, llevar esta figura a cada una de las comisiones en los ámbitos estatal y del Distrito Federal.

Fue evidente la práctica de conductas que violentaron el Cofipe, es por ello que las y los actores políticos y la sociedad insisten en una reforma que dote a la autoridad electoral federal de nuevas atribuciones que le permitan un mayor control del proceso electoral en ámbitos

2 Véase artículo 27 del Cofipe. 
Esta revista forma parte del acervo de la Biblioteca Jurídica Virtual del Instituto de Investigaciones Jurídicas de la UNAM

como la reglamentación de precampañas y campañas, y contratación de medios electrónicos para su difusión, así como el monitoreo de medios.

Para efectos de la justicia electoral, no podemos dejar de mencionar que la reforma electoral y la nueva reglamentación contempla procesos sancionadores y medidas cautelares para afrontar las violaciones al Cofipe, tratándose de propaganda en radio y televisión, y que radica en la posibilidad de suspender de manera inmediata actos que se considere vulneran las normas electorales, en términos de que la medida que se tome será preventiva en un plazo no mayor de 24 horas, y sin prejuzgar sobre la veracidad de los hechos, así también, la medida pude ser de oficio o por denuncia ante el Consejo General y la Comisión de Quejas y Denuncias, ambas del IFE. ${ }^{3}$

Se tomó debida nota de la presentación de los procedimientos administrativos ordinarios sancionadores; especiales sancionadores, de las solicitudes de medidas cautelares, de las quejas en las que se solicitó la aplicación de medidas cautelares, y se constató la debida aplicación del derecho de réplica que el IFE introdujo en el Reglamento de Quejas para efectos de certeza jurídica, en ese tenor, es emblemático el caso de Televisión Azteca, que promovió un recurso de apelación ante el TEPJF, alegando que ni el IFE ni el TEPJF tienen facultad para aplicar de manera directa el artículo 6o. constitucional, en el cual se garantiza el derecho de réplica. Al respecto, el TEPJF resolvió y confirmó la aplicabilidad del Reglamento de Quejas y Denuncias del IFE para resolver esos casos.

El "blindaje" del proceso electoral frente a la situación de violencia, propició la habilidad de la autoridad electoral federal, con base en sus atribuciones, para modificar los protocolos de seguridad y garantizar la seguridad de las elecciones, con ello, las elecciones de 2012 se convirtieron en un tema de seguridad nacional.

Las fases de investigación que realizó la Fundación Estado y Socie$\mathrm{dad}$, repercutieron en la necesidad de realizar modificaciones al Reglamento de Quejas y Denuncias, entre otras, cambios a la normativa sobre cómputos distritales y locales para el recuento de votos. Reformas al Reglamento de Acceso a Radio y Televisión en materia electoral, tratándose de topes de gastos de precampaña y monitoreo de medios; selección de candidatos a cargos de elección popular y precampañas;

3 Véase artículo 365, párrafo 4, del Cofipe. 
campañas electorales; selección de candidatos de los partidos políticos con equidad de género, fiscalización de gastos de partidos políticos en periodos incluso de "intercampañas"; jornada electoral, sobre todo, lo relacionado con la compra y coacción del voto, y finalmente controversias e impugnaciones.

Las propuestas concretas que formula esta organización, se refirieron a ajustes normativos y estratégicos dentro del sistema jurídico mexicano e institucional; como propiciar una cultura en medios de comunicación; procesos jurisdiccionales y su marco organizacional electoral dentro de perspectivas teóricas de "cambio de régimen desde el autoritarismo hacia un mayor espacio de democratización no elitista o de pactos".

\section{Comisión Mexicana de Derechos Humanos, A. C. Proyecto justicia electoral 2012. Una observación a la luz de la reforma constitucional de los derechos humanos}

El análisis se centró en la responsabilidad que tienen las autoridades electorales y los partidos políticos como actores principales en el proceso electoral, ya que ante la sociedad mexicana deben responder respecto a que las elecciones se realicen conforme a derecho, evitando en todo momento cualquier conducta antisocial que pudiera afectar su normal desarrollo.

Asimismo, el informe explica y destaca que la tarea más compleja e importante del IFE fue la de conseguir encausar la contienda en un ambiente de equidad, donde los partidos políticos y sus candidatos se condujeran con estricto apego a la legalidad; la de impulsar la propuesta política en lugar del desprestigio, vigilar y llevar a buen puerto las alianzas y pactos políticos suscritos en el marco de la ley, y "erigirse como el primer y gran responsable de éxito de la organización de la elección".

En materia de delitos electorales, el órgano con autonomía técnica, la Fiscalía Especializada para la Atención de Delitos Electorales (FEPADE), refrendó su colaboración con el IFE y el TEPJF, para que los procesos electorales federales se realizaran con equidad, legalidad y transparencia. Tuvo la gran tarea de velar porque las y los ciudadanos pudieran participar con libertad absoluta y los actores políticos com- 
Esta revista forma parte del acervo de la Biblioteca Jurídica Virtual del Instituto de Investigaciones Jurídicas de la UNAM

pitieran en igualdad de condiciones. Para ello, realizó diferentes programas para prevenir que ningún servidor público se aprovechara de su condición para beneficiar o perjudicar a quienes participan como actores políticos en el proceso electoral.

Desde su concepción, el IFE tiene entre sus tareas la de organizar el proceso electoral federal, y su reto en la elección de 2012, fue recuperar la confianza y credibilidad de los ciudadanos, no solamente en la propia institución, sino en el proceso electoral. ¿Y cómo lo logró? Garantizando que las elecciones se llevaran a cabo de manera pacífica, sin violencia. En ese sentido, se observó que en la toma de decisiones de cada etapa del proceso electoral, actuó conforme a derecho y contribuyó al "desarrollo, salud y consolidación de la democracia electoral en México”.

En el tema de cuotas de género, el TEPJF manifestó que "se obtuvo una armónica composición de las normas contenida en el reglamento emitido por la autoridad electoral federal", con ello se garantizó el cumplimiento de las cuotas de género que debían satisfacer los partidos políticos al registrar sus fórmulas de candidatos, con el objetivo de "alcanzar una sociedad más igualitaria en la que hombres y mujeres tuvieran las mismas oportunidades para acceder a los cargos públicos de elección popular y de esa forma cumplir además los diversos compromisos internacionales adoptados por el Estado mexicano".

También en el ámbito de las resoluciones emitidas por el TEPJF, es de destacarse lo sustanciado en el caso de los spots del Morena, en donde el máximo órgano jurisdiccional sentó precedente al no entrar al fondo de la resolución porque no examinó el "punto toral" de los agravios, consistente en determinar si los spots tuvieron un impacto publicitario en favor del precandidato Andrés Manuel López Obrador y si dicha publicidad pudo haber causado un rebase de los topes máximos del financiamiento de precampaña o si el mismo constituyó un acto anticipado de campaña. Se justificó indicando que el análisis le corresponde al IFE, a través de la Unidad de Fiscalización, lo que estimó constitucional y legal, atendiendo la reforma al artículo 41, base $\mathrm{V}$ de la CPEUM, que crea a la Unidad de Fiscalización como unidad técnica que goza de autonomía de gestión, aun cuando la Comisión

4 El Instituto Federal Electoral, dio cuenta del cumplimiento de los artículos 219 y 220 del Cofipe, sustentado en la Convención para Erradicar todas las formas de Discriminación hacia la Mujer, CEDAW, por sus siglas en inglés. 
Esta revista forma parte del acervo de la Biblioteca Jurídica Virtual del Instituto de Investigaciones Jurídicas de la UNAM

Mexicana de Derechos Humanos A.C., indicó que "es de suyo irracional y no favorece la democracia del país".

Tampoco se omite indicar que en la Jornada Temática se puntualizó en que la Unidad Técnica de Fiscalización no es supervisada ni vigilada permanentemente por los consejeros electorales del IFE, sino que éstos se enteran de cada auditoría, incluso, tan solo unos instantes antes que la opinión pública, es decir, cuando ya está definido y sin tener margen de tiempo para analizar. En ese sentido se hizo patente que debe entenderse que la autonomía técnica de esa Unidad es exclusivamente de gestión, para asuntos administrativos, ya que la Constitución no la dota de autonomía técnica como en el caso de la Contraloría General.

En el esquema de las candidaturas independientes, se analizaron diversas resoluciones del TEPJF, y se concluyó que el sistema de partidos políticos que actualmente contempla la ley para acceder a cargos de elección popular es obsoleto, ya que no contempla esta figura, lo que implica la existencia de un "monopolio en manos de los partidos políticos" y que ciudadanos apartidistas no ejercen plenamente su derecho a ser votados. ${ }^{5}$ También en justicia cabe indicar que la Sala Superior del TEPJF estableció en algunas de sus resoluciones, la motivación que sustenta una probable reforma constitucional y legal que busque además el cumplimiento pleno y palpable de los derechos humanos reconocidos por la Constitución y tratados internacionales.

En el rubro del voto en el extranjero, se tiene claro que "el Estado mexicano debe prever un mecanismo adecuado para que todos los ciudadanos mexicanos residentes en el extranjero efectivamente gocen del derecho a votar", incorporar en el Cofipe un dispositivo para que los connacionales se registren desde su lugar de residencia y exista la instancia administrativa in situ para la obtención de la credencial de elector.

En materia de atribuciones de las principales autoridades en materia electoral, la FEPADE ha implantado programas de blindaje electoral pero únicamente encaminado a los servidores públicos, y en cuanto a la investigación y persecución de los delitos, son pocas las averiguaciones previas que se consignan y mucho menos en las que se libra orden de aprehensión. Al respecto, se estimó que debería considerarse

5 Esta observación, se ve superada por la reciente reforma política, que incluye al artículo 35 constitucional, publicada el 12 abril de 2012, en la que se deberán considerar los extremos necesarios para hacer válidas las candidaturas independientes. 
Esta revista forma parte del acervo de la Biblioteca Jurídica Virtual del Instituto de Investigaciones Jurídicas de la UNAM

en su ámbito de competencia, no sólo a los servidores públicos, sino a otros actores políticos, como los partidos.

El informe que se analiza, considera el aspecto de perfeccionamiento de la organización de las elecciones, y en este sentido, el IFE ha mejorado su logística para la instalación de casillas pero sigue pendiente una adecuada capacitación de los funcionarios, ya que al momento de la votación, se les presentaron algunos problemas que no sabían cómo resolver.

Como corolario se indicó en general que las resoluciones el TEPJF fueron tomadas con apego a lo establecido en las normas; los partidos políticos realizaron conductas antijurídicas, como la compra del voto y el rebase de presupuestos a las campañas; el IFE tuvo la tarea compleja e importante de lograr encausar la contienda en un ambiente de equidad, donde los partidos políticos y sus candidatos se condujeran con estricto apego a la legalidad, impulsar la propuesta política ante el desprestigio, vigilar que las alianzas y pactos políticos se encuadren en el marco de la ley.

\section{Ciudadanos en Movimiento para el Desarrollo A. C. (CiudaDes)}

El informe que se estudia da cuenta de las campañas electorales, redes sociales y jornada electoral, y cómo impactan en la legalidad electoral. Se identificaron las estrategias de campaña de los candidatos presidenciales a través de su presencia en medios de comunicación; se conocieron las manifestaciones de candidatos y sociedad en las redes sociales e Internet y el desarrollo de la jornada en términos de la actuación de la autoridad electoral, partidos políticos y ciudadanía.

El análisis arrojó que en general persiste la desconfianza en el tema del marketing político, porque torna a las campañas y sus mensajes como algo sintético, con simplificación de ideas y contenidos, pero al final, esta herramienta puede explicar por qué el triunfo de un determinado candidato y cuál fue el mensaje que mejor impacto provocó en el electorado.

Durante la jornada electoral, se concluye que hubo descalificaciones y cuestionamientos por "supuestas" malas conductas institucionales, civiles y mediáticas. Se dieron múltiples denuncias por irregularida- 
des, las más recurrentes se refirieron a la compra de votos, pero también las hubo por robos con violencia de urnas, así como por agresiones contra ciudadanos de las diferentes fórmulas y por manipulación indebida de papelería electoral por presuntos operadores, aun cuando el IFE no reportó estos hechos de violencia.

Por otro lado, indica que la elección tuvo una notable virtud: la alta participación ciudadana y el resurgimiento de un interés cívico que restableció el vínculo con las urnas y con la política en general de grandes sectores de la ciudadanía. Independientemente de las provocaciones y descalificaciones que se dieron tanto en la campaña como en la jornada electoral, entre los partidos y candidatos, incluso entre las diferentes instancias del gobierno, los ciudadanos no participaron en ellas, asumiendo una actitud de interés que se tradujo en una alta participación.

En materia de denuncias públicas de supuesta compra de votos, destaca el informe, que no pudieron ser documentadas en términos de ley. En general una "jornada tranquila”, con incidentes que no cambian el resultado de la elección.

El informe aporta una relación con los puntos positivos y negativos del proceso electoral, los positivos fueron que se instalaron prácticamente todas las casillas electorales, en cambio, los negativos tuvieron que ver con la falta de coordinación entre el IFE y los órganos electorales locales con elecciones concurrentes; reiteradas denuncias por rebase de topes de campaña; problemas de organización para la acreditación de observadores electorales y litigios mediáticos de situaciones que debieron ser resueltas en los órganos jurisdiccionales.

\section{El Colegio de México}

1. ¿Inconsistencias, o irregularidades? La calidad de las elecciones de 2012 a la luz de la estadística y geografía de los resultados, así como de la dinámica de las impugnaciones y conflictos (pos-) electorales

El análisis del informe de mérito, cita textualmente que:

... La evaluación de la calidad y la percepción de la legitimidad de las elecciones fueron, de suyo, paradójicas. Muchos mexicanos dudan hoy en 
Esta revista forma parte del acervo de la Biblioteca Jurídica Virtual del Instituto de Investigaciones Jurídicas de la UNAM

\begin{abstract}
día de la calidad de sus procesos electorales, cuestionan abiertamente su elevado costo y manifiestan públicamente sus reservas sobre la confiabilidad de sus resultados. La percepción no solamente se da entre los sectores más desinformados y despolitizados de la ciudadanía, está compartida por segmentos de las élites políticas económicas y culturales del país.
\end{abstract}

Se trató de una elección competida y plural, con resultados técnicamente precisos y confiables, pero que fueron rechazados por el candidato que alcanzó el segundo lugar, dándoles un importante déficit de legitimidad.

El informe arroja un comparativo interesante al indicar que mientras que en la elección de 2006, la Coalición por el Bien de Todos solicitaba la reparación de irregularidades precisas relacionadas con el cómputo de los sufragios, en 2012 el juicio de inconformidad presentado por el Movimiento Progresista exigió directamente la anulación de toda la elección presidencial. Pese a que dicho juicio de inconformidad se enfocó en una impugnación mucho más amplia de la inequidad de las elecciones para demostrar su invalidez constitucional, éste también cuestiona la certeza del escrutinio de los votos, asumiendo y sugiriendo que las incongruencias registradas en numerosas actas de casilla contribuyeron a comprobar la irregularidad de los comicios presidenciales.

La calidad técnica de las elecciones partió de premisas y cuestionamientos muy puntuales, relativos al registro de diferencias importantes entre las listas nominales del PREP y del Cómputo Distrital; efectos políticos concretos de las votaciones atípicas registradas en bases de datos; recuento realizado por el IFE en más de 78000 casillas; diferencias observadas entre los totales de votos en las elecciones para presidente, senadores y diputados, y el incremento "anormal y sospechoso" de la lista nominal en casillas rurales. Al respecto, coexisten y se enfrentan dos visiones radicalmente opuestas sobre la calidad técnica de las elecciones, los comicios se llevan a cabo en condiciones ideales, y en ellos cada sufragio se cuenta y se registra con precisión, y un segundo sector desconfía profunda y obstinadamente de los procesos electorales y los imagina como "cochineros" plagados de errores e irregularidades.

No todas las inconsistencias se deben a actos dolosos para alterar los resultados, el análisis de los datos desagregados en el nivel de las casillas arrojó un número importante de anomalías sin que afectaran 
Esta revista forma parte del acervo de la Biblioteca Jurídica Virtual del Instituto de Investigaciones Jurídicas de la UNAM

de forma significativa y determinante los porcentajes obtenidos por las distintas fuerzas partidistas. Diversos errores también pueden ocurrir a lo largo de la jornada electoral y ser ocasionados por los mismos votantes, pero muchas veces subsanados o compensados en cuanto los resultados son agregados a nivel seccional, distrital, estatal y federal. En resumen, resulta estimable e inevitable que en el proceso se cometan errores humanos.

Los esquemas de inconsistencias e irregularidades se asociaron exclusivamente con errores humanos, tratándose de las primeras, y las segundas definitivamente remiten a manipulaciones deliberadas y proscritas en vistas de alterar los resultados.

Definitivamente las inconsistencias señaladas por el movimiento progresista no derivaron necesariamente en irregularidades manifiestas ni en actos dolosos de manipulación fraudulenta. En esta elección, las casillas con comportamientos sospechosos no solamente se redujeron drásticamente, sino que dejaron de producirse sistemáticamente.

También se analizaron errores que sí podrían relacionarse con actos fraudulentos como lo fueron el relleno de urnas y las "casillas zapato", en las que todos los votos válidos benefician al mismo partido político; cuando el número de boletas anuladas es superior al número de votos con el que el partido más votado aventaja a la segunda fuerza.

Una de las características de las elecciones en México de 2102, fue el significativo incremento en la utilización de los diversos recursos que prevé la ley para impugnar algún proceso de la elección y en su conjunto. Todos los actores optaron por el camino establecido por la ley para resolver las diferencias.

En ese tenor, los recursos interpuestos antes de la jornada electoral sentaron precedentes importantes para el TEPJF, los dos temas fundamentales fueron: la distribución de los tiempos en radio y televisión para los partidos y coaliciones, y los temas relacionados con los procedimientos electorales en materia de la legitimidad de las autoridades electorales locales y distritales.

En la resolución del "recurso madre", 6 para declarar infundados los agravios, el TEPJF debía entrar al fondo del análisis en cada caso, así lo hizo y así lo manifestaron los magistrados:

6 Denominación que se le otorgó a la impugnación hecha valer por la Coalición Movimiento Progresista. 
Esta revista forma parte del acervo de la Biblioteca Jurídica Virtual del Instituto de Investigaciones Jurídicas de la UNAM

a) La coalición no acreditó sus pretensiones concretándose a formular cuestiones subjetivas, carente de sustento legal y probatorio.

b) Reiteró su posición sobre la falta de elementos probatorios idóneos que pudieran establecer la compra y coacción del voto antes, durante y después de la jornada electoral, mediante la entrega de beneficios diversos a la población en general, pero en especial en las zonas más pobres del país.

c) Concluye contundentemente que los resultados de la elección presidencial no carecen de certeza y que las diferencias de que se duele la coalición quejosa, son producto, o de las características mismas del proceso electoral o de errores menores que fueron analizados en extenso, sin que hubiera base para dar crédito a la queja generalizada que formuló la Coalición Movimiento Progresista.

Todo el sistema mexicano está diseñado para que las elecciones sean impugnadas jurídicamente. En efecto, mucho de lo que se impugnó tiene que ver con la materia de controversia y objetivo del actor quejoso. La percepción de que la democracia mexicana, a pesar de todo, requiere de más y más ajustes, no desaparecerá por lo que haya dicho el TEPJF, eso no habría ocurrido bajo ningún escenario, incluso el de la nulidad de la elección, en ese sentido, además de realizar reformas que, en efecto mejoren el desempeño de las autoridades, de los partidos y de los candidatos, también es necesario desestimular la impugnación como un mecanismo políticamente correcto para las clientelas de cada candidato y partido.

\section{Universidad Autónoma de Chiapas. Diagnóstico de las fortalezas y debilidades de la fiscalización electoral en México}

El informe técnico que se estudia, versó sobre el control del financiamiento y el gasto político electoral, con aristas como la sospecha del uso indiscriminado de recursos financieros de dudosa procedencia, que han estado presentes en diversos procesos electorales de México. En ese sentido, la discusión nacional e internacional sobre la relación entre el dinero y la democracia electoral: 
Esta revista forma parte del acervo de la Biblioteca Jurídica Virtual del Instituto de Investigaciones Jurídicas de la UNAM

Se ha agudizado con el fortalecimiento de los poderes fácticos con amplio margen de financiamiento que superan la capacidad del Estado en muchos países, y que están desafiando la transparencia y equidad de sus procesos electorales, como el crimen organizado o los grandes emporios económicos nacionales y transnacionales.

Al respecto, se propone realzar esfuerzos regulatorios para garantizar las condiciones de equidad de la competencia electoral, propiciar la transparencia de los gobiernos electos y fortalecer la confianza ciudadana. Es impostergable crear los mecanismos efectivos para prevenir el financiamiento ilegal, para detectarlo y sancionarlo, así como llevar a cabo una función fiscalizadora eficiente y oportuna; contar con un marco regulatorio claro y transparente que castigue la conducta ilícita, y promover la profesionalización de los servidores que administran los recursos públicos.

Se pone de manifiesto que la Unidad de Fiscalización del IFE tiene como debilidad no contar con una estructura propia desconcentrada, y hoy por hoy, requiere de la colaboración de las juntas ejecutivas locales y distritales en actividades procedimentales como las notificaciones, requerimientos de información y de seguimiento. Pero tuvo la fortaleza de haber recuperado el secreto profesional, lo que se traduce en una consecuencia lógica de la diligencia y responsabilidad con que se desarrollan las modernas técnicas de auditoría.

Se destacan esquemas muy específicos y de los cuales también se aportan conclusiones, hallazgos y recomendaciones puntuales, mismas que en seguida se relacionan, aun cuando existe un gran avance en materia de fiscalización, y algunas de estas recomendaciones han sido superadas por la reforma constitucional, como se puede apreciar en los artículos 77, 79, 81, 84 y 85 del Cofipe:

a) Establecimiento de reglas de financiamiento. El financiamiento electoral constituye el medio indispensable para la consolidación de cualquier democracia; el modelo mixto adoptado por México requiere regulaciones específicas para su cumplimiento eficaz, como el replanteamiento de los topes de financiamiento privado; es necesario regular el financiamiento electoral y el nivel de especificidad para minimizar riesgos de corrupción. El control del financiamiento electoral en México encuentra su principal desafío en la tendencia partidista de no reportar las cuantiosas apor- 
Esta revista forma parte del acervo de la Biblioteca Jurídica Virtual del Instituto de Investigaciones Jurídicas de la UNAM

taciones privadas que recaban durante las campañas. La agenda para el mejoramiento del control y una mayor transparencia de la financiación electoral en México, pasa por la revisión de las reglas restrictivas del financiamiento privado, a través de medidas realistas y procesos de transparencia en los ingresos de los partidos políticos y candidatos, para lograr mayores condiciones de igualdad de oportunidades inhibiendo la corrupción.

b) Establecimiento de reglas de gasto electoral. Se requiere de regulación tanto de ingreso como de egreso y establecimiento de topes y restricciones de gasto para generar igualdad de oportunidades, control de gasto y prevenir financiamiento ilegal.

c) Planeación del programa de fiscalización. La planeación debe contemplar los objetivos de la revisión, la evaluación de riesgos, el alcance de la auditoría, los rubros a revisar, la metodología y los procedimientos, y definir a los profesionistas que intervengan.

d) Desarrollo y ejecución ex post. El problema de que la fiscalización inicie una vez que los partidos políticos presentan sus informes financieros, es que los plazos de su presentación son extensos, por lo que la fiscalización se retrasa.

e) Desahogo de procedimientos de revisión de informes financieros y auditoría contable a los controles internos partidistas. Los partidos deben adoptar un sistema contable para registros, clasificación y resumen de las operaciones que servirán de base para interpretar los resultados de sus operaciones de ingresos y egresos.

f) Acompañamiento de controles indirectos con el objetivo de verificar la información reportada, que se desarrollan concurrentemente a las campañas o durante el proceso de revisión de los informes. Son procedimientos necesarios toda vez que en la auditoría a las finanzas formales se puede detectar si un partido utilizó con apego a derecho los recursos que declaró haber recibido.

g) Incorporación de instrumentos de investigación con el objetivo de poder ampliar la información cuando sea necesario. Uno de los principales instrumentos de investigación, es la obligación de personas físicas y morales de atender los requerimientos de información. Un instrumento complementario es solicitar a la autoridad hacendaria para que realice una auditoría a determinada persona física o moral, de modo que pueda hacerse de mayores elementos para conocer la verdad sobre un hecho opaco. 
Esta revista forma parte del acervo de la Biblioteca Jurídica Virtual del Instituto de Investigaciones Jurídicas de la UNAM

h) Presentación de un informe final de resultados, con conclusiones y recomendaciones. El objetivo es dar seguimiento a efecto de verificar correcciones, prevenciones y establecimiento de medidas cautelares. Debe estar apoyado en una metodología soportada por el uso de las mejores prácticas administrativas y tecnológicas.

i) Reconocimiento de un periodo de solventación de las observaciones emitidas.

j) Establecimiento de un régimen sancionador. La principal debilidad del régimen de sanciones en México parece derivarse de la imposibilidad por parte de la autoridad para sancionar con la nulidad de la elección en caso de violaciones graves, como sería el caso del determinante rebase a los topes de gasto establecidos en una campaña. Dentro de las acciones pendientes se encuentra la exploración de otros factores que influyen en la debilidad del régimen sancionador que acompaña a los procedimientos de fiscalización, como la naturaleza del propio IFE o ente fiscalizador.

A manera de conclusión:

Los análisis dan cuenta de los temas a trabajarse en una reforma constitucional y legal, no obstante, algunos de los informes reportan reformas constitucionales publicadas en el Diario Oficial de la Federación, como sería la relativa a candidaturas independientes, así como el avance que se da en materia de fiscalización de los recursos de los partidos políticos.

Debe analizarse la responsabilidad que tienen los partidos políticos nacionales en el desarrollo adecuado de la democracia mexicana, para exhibir una responsabilidad no sesgada exclusivamente hacia las autoridades electorales observadas. De esta forma se garantizaría la protección y defensa de los derechos humanos políticos. Es indudable que las resoluciones de las autoridades electorales, el IFE y el TEPJF, son un insumo importante y palpable para emprender esa tarea.

"No se puede hablar de una buena elección si no existe una buena administración", en efecto, hoy por hoy el IFE desarrolla la función constitucional y legal de organizar las elecciones federales que va, necesariamente, aparejada con el proceso de legitimación de las mismas; es por esto que los insumos arrojados en los informes deben ser con-

Barrientos del Monte, Fernando, Gestión electoral comparada y confianza en las elecciones en América Latina, México, INAP, 2011. 
Esta revista forma parte del acervo de la Biblioteca Jurídica Virtual del Instituto de Investigaciones Jurídicas de la UNAM

siderados "focos" de atención política, dadas las experiencias que se dieron en el proceso, especialmente cuando se trata de disolver cualquier duda respecto de su confiabilidad, de manera que la sociedad recupere esta confianza que fue mermada por elecciones pasadas, en particular la de 2006.

El derecho no es estático y menos cuando se trata del derecho electoral, en ese sentido, definitivamente es oportuno, constitucional, legal y procesalmente, dar preeminencia al IFE, y propiciar las más amplias iniciativas de reforma para incorporar cambios pertinentes y profundos al diseño de este organismo electoral federal, con matices que impliquen: desempeñar con más independencia su función; mejorar sus funciones administrativas, incluso, agregaría, constituirla en la institución nacional que organice también las elecciones locales.

\section{Fuentes consultadas}

Barrientos del Monte, Fernando, Gestión electoral comparada y confianza en las elecciones en América Latina, México, INAP, A.C., 2011.

Código Federal de Instituciones y Procedimientos Electorales (Cofipe) Diario Oficial de la Federación, 13 de noviembre de 2007, 14 de enero de 2008, 10 de junio de 2011.

Jornada Temática Observación Electoral en México: Lecciones aprendidas y visión a futuro, celebrada en la Facultad Latinoamericana de Ciencias Sociales sede México el 15 de noviembre de este año. 